\section{Diagnosis and treatment of HIV-associated manifestations in otolaryngology}

\section{Emily lacovou, ${ }^{1}$ Petros V. Vlastarakos, ${ }^{2}$ George Papacharalampous, ${ }^{3}$ George Kampessis, ${ }^{4}$ Thomas P. Nikolopoulos 5}

${ }^{1}$ General Hospital of Larnaca, Cyprus; ${ }^{2}$ Lister Hospital, Stevenage, UK; 3Penteli Children's Hospital, Greece; ${ }^{4}$ Royal Sussex County Hospital, UK; ${ }^{5}$ Atticon University Hospital, Greece

\section{Abstract}

Almost 30 years after its first description, HIV still remains a global pandemic. The present paper aims to review the current knowledge on the ear, nose and throat (ENT) manifestations of HIV infection, and present the available diagnostic and treatment options. A literature review was conducted in Medline and other available database sources. Information from related books was also included in the data analysis. It is well acknowledged that up to $80 \%$ of HIV-infected patients eventually develop ENT manifestations; among which, oral disease appears to be the most common. Oro-pharyngeal manifestations include candidiasis, periodontal and gingival disease, HSV and HPV infection, oral hairy leucoplakia, Kaposi's sarcoma, and nonHodgkin's lymphoma. ENT manifestations in the neck can present as cervical lymphadenopathy or parotid gland enlargement. Respective nasal manifestations include sinusitis (often due to atypical bacteria), and allergic rhinitis. Finally, otological manifestations include otitis (externa, or media), inner ear involvement (sensorineural hearing loss, disequilibrium), and facial nerve palsy (up to 100 times more frequently compared to the general population). Although ENT symptoms are not diagnostic of the disease, they might be suggestive of HIV infection, or related to its progression and the respective treatment failure. ENT doctors should be aware of the ENT manifestations associated with HIV disease, and the respective diagnosis and treatment. $\mathrm{A}$ multi-disciplinary approach may be required to provide the appropriate level of care to HIV patients.

\section{Introduction}

Almost 30 years after its first description, ${ }^{1}$ HIV still remains a global pandemic, particularly affecting the countries of sub-Saharan Africa, Southeast Asia, and Latin America. HIV is an RNA retrovirus which compromises the immune system, and renders the infected person susceptible to opportunistic infections and malignancy.

The incidence of HIV infection in 2009 was 2.6 million, whilst the respective prevalence ranged between 31.4-35.3 million people. The prevalence of HIV had risen by $27 \%$ compared to the previous decade, although the annual rate of new cases had been steadily declining since the late 1990s. In addition, the estimated number of children living with HIV increased to approximately 2.5 million in 2009 .

The increased incidence of HIV has resulted in a greater number of HIV-infected patients presenting to ENT doctors. Indeed, up to $80 \%$ of HIV-infected patients eventually develop ENT manifestations..$^{2-4}$ Among the latter, oral disease seems to be the most common, occurring in approximately 40-50\% of HIV positive patients. ${ }^{5}$ Predisposing factors for HIV-related ENT conditions include CD4+ cell count of less than $200 / \mu \mathrm{L}$, plasma HIV-RNA levels greater than 3000 copies/mL, xerostomia, poor oral hygiene, and smoking. ${ }^{6,7}$

Although ENT manifestations may not be diagnostic of HIV infection, they may be heavily suggestive of such an infection. ${ }^{8}$ In addition, the occurrence of certain oral manifestations in patients with known HIV disease who are not receiving treatment may be related to the progression of the disease. ${ }^{8}$ Finally, the presence of ENT disease in patients on antiretroviral therapy could be the result of an increase in the plasma HIV-RNA and suggest treatment failure. ${ }^{8-10}$ In this context, the provision of appropriate care to HIV patients may require a multi-disciplinary approach.

The aim of the present paper is to review the current knowledge on ENT manifestations of HIV infection, and present the available diagnostic and treatment options. The implications of the early identification of HIV-associated ENT disease from a public health perspective are also discussed, along with clinical markers of immune compromise.

\section{Oro-pharyngeal manifestations of HIV infection}

Oral candidiasis, commonly known as thrush, is by far the most common oral manifestation of HIV infection. Candidal infection can occur in the oropharynx, hypopharynx, and larynx, and usually results in severe odynophagia and swallowing difficulties. The prevalence of candidiasis varies from 30-90\% among HIV
Correspondence: Petros V. Vlastarakos, Lister Hospital, Coreys Mill Lane, Stevenage, Hertfordshire, SG1 4AB, UK.

Tel. +44.1438488837 - Fax: +30.2109714870 .

E-mail: pevlast@hotmail.com

Key words: HIV, AIDS, ear, nose, throat, oral.

Contributions: EI wrote the article; PVV study concept and wrote the article; GP and GK literature research and wrote the article; TPN study overview and wrote the article.

Conflict of interest: the authors report no conflicts of interest.

Received for publication: 1 August 2011.

Revision received: 9 October 2011.

Accepted for publication: 28 October 2011.

This work is licensed under a Creative Commons Attribution NonCommercial 3.0 License (CC BYNC 3.0).

(C) Copyright E. Iacovou et al., 2012

Licensee PAGEPress, Italy

Infectious Disease Reports 2012; 4:e9

doi:10.4081/idr.2012.eg

positive adult patients ${ }^{4,11,12}$ whereas the respective percentage in children ranges between 22.5 and $83.3 \% .^{13}$

Oral candidiasis can present in three forms: pseudomembranous candidiasis, erythematous candidiasis, and angular cheilitis (Figures 1-3). ${ }^{14}$ Oral pseudomembranous candidiasis is the most common fungal infection in HIV disease. It has been associated with more frequent progression of HIV to AIDS, and also used as a clinical marker to define the severity of HIV infection. ${ }^{15}$ It appears as creamy, white, curd-like plaques on the buccal mucosa, tongue, and other oral mucosal surfaces. The plaques can be wiped away, leaving a red or bleeding underlying surface. The most common organism involved is Candida albicans; however involvement of non-albicans species, such as Candida glabrata and Candida dubliniensis, has also been described..$^{16,17}$

Erythematous candidiasis, on the other hand, presents as a red, flat, subtle lesion on the dorsal surface of the tongue, or on the hard or soft palate. The lesion often involves two opposing surfaces, i.e. if a lesion is present on the tongue, the palate should be examined for a matching lesion, etc. Patients usually complain of a burning sensation, especially while eating spicy or salty food. When the hypopharynx, larynx, or esophagus are affected, symptoms may progress to severe odynophagia and swallowing difficulties. This may be especially true in children, in which candidal esophagitis may require hospital admission, and intravenous administration of amphotericin B. ${ }^{18}$ Diagnosis is based on the clinical appearance 
of the lesions taking into consideration the history of HIV infection. However, candidiasis can be confirmed in challenging cases from the identification of fungal hyphae or blastospores in potassium hydroxide $(\mathrm{KOH})$ preparation. ${ }^{8}$

Treatment of mild to moderate cases of both erythematous and pseudomembranous candidiasis includes clotrimazole troches, nystatin oral suspension, and nystatin pastilles, whereas systemic administration of fluconazole, intraconazole and voriconazole is warranted in moderate to severe cases (Table 1). Voriconazole should be reserved for cases of fluconazole resistance, due to more serious iteractions with other drugs. ${ }^{8}$ Antifungal therapy should last for two weeks to reduce the colony forming units to the lowest level possible and prevent recurrence.

Angular cheilitis presents as erythema, and/or fissuring in the corners of the mouth. It may co-exist with erythematous or pseudomembranous candidiasis, and persist for an extensive period of time if left untreated. Treatment involves the use of a topical antifungal cream directly applied to the affected areas four times a day for two weeks.

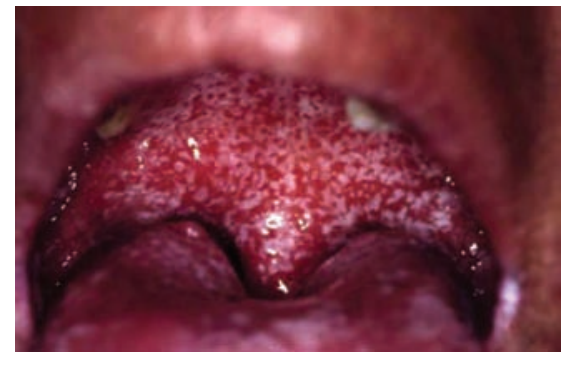

Figure 1. Oral pseudomembranous candidiasis. ${ }^{8}$ Reproduced with permission from IAS-USA. Top HIV Med 2005;13: 143-8.

Periodontal and gingival disease is frequently seen in patients with HIV. The prevalence varies between $0-47 \%$ in adults ${ }^{19}$ and 0 to $20 \%$ in children. ${ }^{20}$ It most commonly presents as plaques similar to the ones found in nonHIV populations.

Linear gingival erythema (Figure 4) presents as a red band along the gingival margin, accompanied by occasional bleeding and discomfort. It most frequently appears at the anterior teeth, but can also extend to the posterior teeth. It can also present on attached and non-

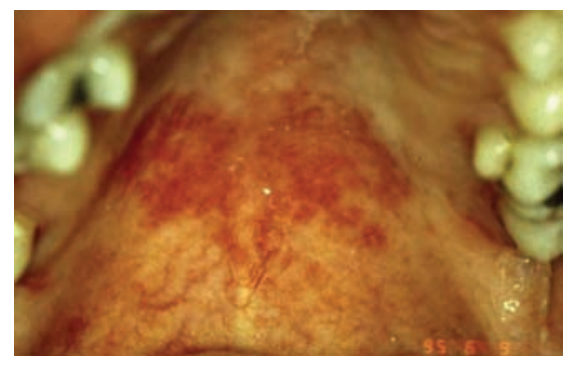

Figure 2. Erythematous candidiasis. ${ }^{8}$ Reproduced with permission from IASUSA. Top HIV Med 2005;13:143-8.

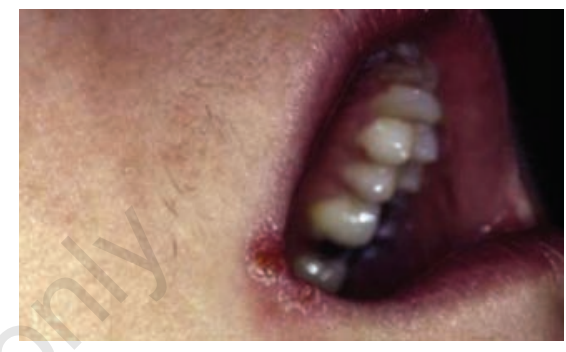

Figure 3. Angular cheilitis. ${ }^{8}$ Reproduced with permission from IAS-USA. Top HIV Med 2005;13:143-8.

Table 1. Treatment regimens for HIV-associated ear, nose and throat (ENT) manifestations in adults and children.

\begin{tabular}{|c|c|c|}
\hline HIV manifestation & Treatment in adults & Treatment in children \\
\hline Oral candidiasis & $\begin{array}{l}\text { Topical agents } \\
\text { Clotrimazole troches } 10 \mathrm{mg} \text { : dispense } 70 \text {, } \\
\text { dissolve } 1 \text { troche in mouth } 5 \text { times a day for } 14 \text { days } \\
\text { Nystatin oral suspension } 500,000 \mathrm{U} \text { : Swish } 5 \mathrm{~mL} \text { in mouth } \\
\text { as long as possible then swallow (optional), qds for } 14 \text { days } \\
\text { Nystatin pastilles } 100,000 \mathrm{U} \text { : dispense } 56, \\
\text { dissolve } 1 \text { in mouth qds for } 14 \text { days } \\
\text { Systemic agents } \\
\text { Fluconazole } 100 \mathrm{mg} \text { : dispense } 15 \text { tablets, take } 2 \text { tablets on day } 1 \text {, } \\
\text { followed by } 1 \text { tablet od for the remainder of the } 14 \text {-day treatment period } \\
\text { Itraconazole oral suspension } 10 \mathrm{mg} / 10 \mathrm{~mL} \text { : dispense } 140 \mathrm{~mL} \text {, swish and swallow } \\
10 \mathrm{~mL} \text { per day for } 7 \text {-14 days. Take medication without food. } \\
\text { Voriconazole } 200 \mathrm{mg} \text { : dispense } 14 \text { tablets, take } 1 \text { tablet bd for } 2 \text { weeks } \\
\text { or at least } 7 \text { days following resolution of symptoms }\end{array}$ & $\begin{array}{l}\text { Topical agents } \\
\text { Nystatin 200,000-800,000 U: used qds, or } 5 \text { times a day } \\
\text { Miconazole 200,000-800,000 U: qds to } 5 \text { times a day. } \\
\text { Oral nystatin } 200,000 \mathrm{U} \text { : in tablets dissolve } \\
1 \text { in the mouth } 5 \text { times a day } \\
\text { Systemic agents } \\
\text { Fluconazole or ketoconazole } 6 \mathrm{mg} / \mathrm{kg} \text { of } \\
\text { body weight for } 5-7 \text { days } \\
\text { Clotrimazole } 10 \mathrm{mg} \text { bd }\end{array}$ \\
\hline Angular cheilitis & $\begin{array}{l}\text { Miconazole cream apply qds for } 14 \text { days } \\
\text { Ketoconazole cream apply qds for } 14 \text { days }\end{array}$ & $\begin{array}{l}\text { Miconazole cream apply qds for } 14 \text { days } \\
\text { Ketoconazole cream apply qds a day for } 14 \text { days }\end{array}$ \\
\hline Necrotizing periodontitis & $\begin{array}{l}\text { Metronidazole } 500 \mathrm{mg}: 1 \text { tablet bd for } 7-10 \text { days. } \\
\text { Amoxicillin } 500 \mathrm{mg} \text { : tds for } 7-10 \text { days. } \\
\text { Clindamycin } 150 \text { to } 300 \mathrm{mg} \text { : qds for 7-10 days. } \\
\text { for } 7-10 \text { days. } \\
\text { Clindamycin } 8-16 \mathrm{mg} / \mathrm{kg} / \text { day }(4-8 \mathrm{mg} / \mathrm{b} / \text { day) divided }\end{array}$ & $\begin{array}{l}\text { Metronidazole } 15-30 \mathrm{mg} / \mathrm{kg} / \text { day orally in } 3 \text { divided } \\
\text { doses tds for } 7-10 \text { days } \\
\text { Amoxicillin } 40 \mathrm{mg} / \mathrm{kg} / \text { day in divided doses tds } \\
\text { into } 3 \text { or } 4 \text { equal doses for } 7-10 \text { days. }\end{array}$ \\
\hline Oral HSV & $\begin{array}{l}\text { Acyclovir } 800 \mathrm{mg}, 5 \text { times a day for } 7-10 \text { days } \\
\text { Famciclovir } 500 \mathrm{mg} \text { tds for } 7 \text { days }\end{array}$ & $\begin{array}{l}\text { Acyclovir } 10 \mathrm{mg} / \mathrm{kg} \text { qds or } 5 \text { times per day*. } \\
\text { HSV prophylaxis: Acyclovir } 10 \mathrm{mg} / \mathrm{kg} \text { bd, or tds }\end{array}$ \\
\hline Sinusitis & $\begin{array}{l}\text { CD4>200 cells/mm }{ }^{3} \\
\text { Amoxicillin } 1.5-4 \mathrm{~g} / \text { day } \\
\text { Amoxicillin/clavulanate: } 1.75-4 / 250 \mathrm{~g} / \text { day } \\
\text { Cefuroxime axetil } 500 \mathrm{mg} \text { bd } \\
\text { Trimethoprim/sulfamethoxazole: } 160 \mathrm{mg}-800 \mathrm{mg} \text { orally bd } \\
\text { Telithromycin } \\
\text { Erythromycin, clarithromycin, azithromycin } \\
\text { CD4<200 cells/mm }{ }^{3} \text { or failure of above therapy } \\
\text { Fluoroquinolone + clindamycin or metronidazole }\end{array}$ & $\begin{array}{l}\text { Amoxicillin } 40 \mathrm{mg} / \mathrm{kg} / \text { day tds in divided doses } \\
\text { Amoxicillinclavulanate } 125 / 31 \text { tds between } 1-6 \text { years, } \\
\text { 250/62 between } 6-12 \text { years } \\
\text { Cefuroxime axetil } 20-30 \mathrm{mg} / \mathrm{kg} \text { daily given in } 2 \text { divided } \\
\text { doses in children }>4 \text { weeks of age } \\
\text { Trimethoprim/sulfamethoxazole } \\
\text { 6-10 mg/kg/day orally in children }>2 \text { months of age } \\
\text { Erythromycin, clarithromycin, azithromycin }\end{array}$ \\
\hline
\end{tabular}

od, once daily, bd, twice daily; tds, every 8 h; qds, every 6 hbd, twice daily; tds, every 8 h. *Severe cases: Acyclovir $10 \mathrm{mg} / \mathrm{kg}$ iv tds 
attached gingiva as petechia-like patches. A fungal etiology has been reported ${ }^{21,22}$ however antifungal therapy is not required. Treatment includes debridement by the dentist, mouth rinses with a $0.12 \%$ chlorhexidine gluconate suspension twice daily for two weeks, and home oral hygiene.

In contrast, necrotizing gingivitis and necrotizing periodontitis (Figure 5) can result in the rapid destruction of soft tissue in the former and hard tissue in the latter condition. Necrotizing ulcerative periodontitis is a marker of severe immune suppression..$^{23}$ It is characterized by severe pain (often described by patients as deep jaw pain), loosening of the teeth, bleeding, fetid odor, ulcerated gingival papillae, and rapid loss of bone and soft tissue. Intervention is usually intensive curettage and debridement of all involved tissues, and use of topical antiseptic agents, such as $0.12 \%$ chlorhexidine gluconate or $10 \%$ povidoneiodine lavage. More severe cases should be supplemented by a short course of systemic antimicrobial therapy, usually metronidazole. ${ }^{24}$ Clindamycin and amoxicillin have also been recommended. ${ }^{25}$

Oral infections with herpes simplex virus (HSV) (Figure 6) occur in up to 9\% of adults ${ }^{4,11}$ and $1.3-24 \%$ of children with HIV. ${ }^{27-29}$ Oral HSV presents as a small crop of vesicles which produce small, painful ulcerations extending onto the adjacent skin, and may coalesce to form giant herpetic lesions. Although their clinical features are similar to non-HIV infected patients, the lesions are often bigger in HIV patients, recur more frequently, and tend to be more persistent. Lesions most commonly appear on the lips, in the mouth, hard palate, and gums. Although they are typically self-limiting, the use of antiviral agents, such as acyclovir, is sometimes required. HSV ulcers may become chronic in children with severe HIV, and convert into true membranes which may require hospital admission and intravenous administration of acyclovir ${ }^{30}$ (Table 1).

Oral hairy leukoplakia (Figure 7) is a largely asymptomatic condition of the tongue caused by the Epstein-Barr virus. It presents as a white corrugated lesion on the lateral borders of the tongue. The lesion cannot be removed by the patient. The prevalence of oral hairy leukoplakia varies from $0.42-38 \%$ in HIVinfected adults ${ }^{32-34}$ to around $2 \%$ in children. ${ }^{20}$ The terminology of this condition arises from the appearance of elongated filiform papillae which can be accompanied by white plaquelike changes. No treatment is required unless cosmetic concerns arise. ${ }^{8}$ In such cases, good results have been reported with topical application of trichloracetic or glycolic acid, ${ }^{35}$ podophyllum resin solution $25 \% \%^{36}$ and oral acyclovir. $^{37}$

Oral human papilloma-virus infection (HPV) (Figure 8) has increased in the era of highly active antiretroviral therapy (HAART therapeutic regimens) ${ }^{38,39}$ This suggests that a drug or combination of drugs used to treat HIV may be a risk factor for oral HPV infection. ${ }^{40}$ The most common HPV subtypes found in the oral cavity are subtypes 16 and 18, which may be related to oral sexual behavior. The warts may be cauliflower-like, spiked, or raised with a flat surface. Treatment involves surgery (laser, or cryotherapy) which may need to be repeated due to the frequent recurrence of the lesions.

Kaposi's sarcoma (Figure 9) is still the most common oral malignancy seen among patients with HIV. The prevalence of oral Kaposi's sarcoma of the mouth varies from $0-12 \%$ in Africa and $0-38 \%$ in USA and Europe. ${ }^{6,41}$ The oral cavity is commonly affected and is the first clinical site of Kaposi's sarcoma in $20 \%$ of cases, while it occurs concomitantly with skin and visceral involvement in up to $70 \%$ of patients. ${ }^{41}$ Within the oral cavity, the hard palate is the

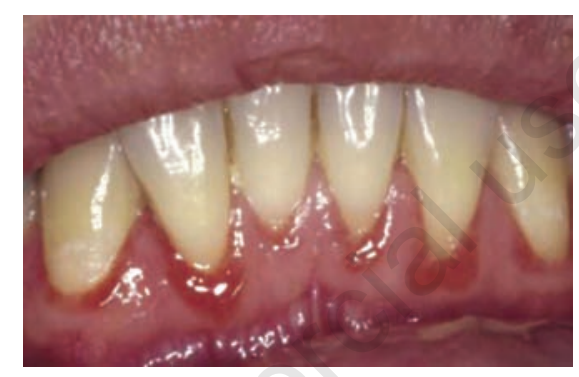

Figure 4. Linear gingival erythema. ${ }^{8}$ Reproduced with permission from IASUSA. Top HIV Med 2005; 13:143-8.

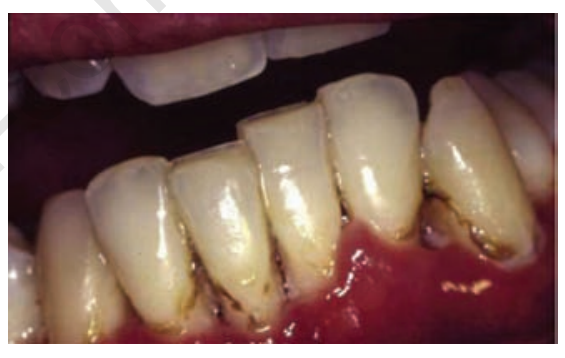

Figure 5. Necrotizing ulcerative periodontitis. ${ }^{8}$ Reproduced with permission from IAS-USA. Top HIV Med 2005;13:143-8.

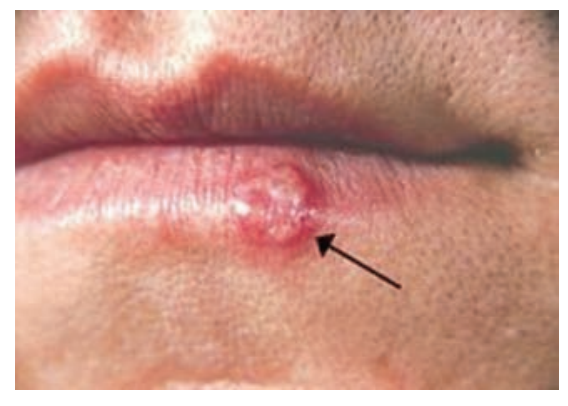

Figure 6. Oral Herpes Simplex virus. ${ }^{26}$ most frequently involved, followed by the gingival and buccal mucosa, as well as the dorsum of the tongue. Kaposi's sarcoma-associated herpes virus was proven to be a co-factor in the presentation of Kaposi's sarcoma in patients with HIV. Kaposi's sarcoma can be macular, nodular, or raised and ulcerated. The color of the lesions can range from red to purple. Early lesions tend to be red, flat and asymptomatic, with the color becoming darker as the lesion ages. As lesions progress, they can become symptomatic due to trauma or infection. Biopsy of the lesion, usually under local anesthetic, is necessary for diagnosis. Following the diagnosis of Kaposi's sarcoma, oral hygiene is necessary, and topical injections of chemotherapeutic agents, such as vinblastine sulfate, or even surgical removal or radiation therapy can be considered for treatment. Several surgical techniques have been described, including cryotherapy and laser therapy. ${ }^{42,43}$ Systemic chemotherapy should be

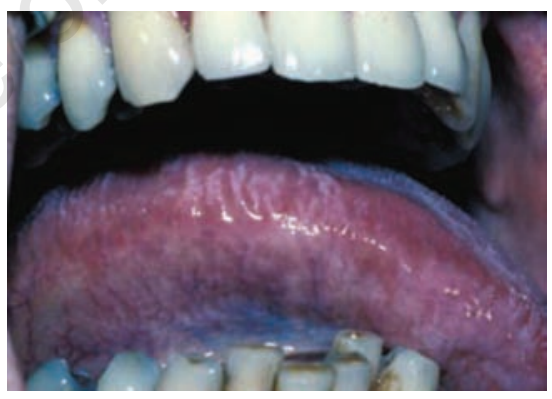

Figure 7. Oral hairy leukoplakia. ${ }^{31}$

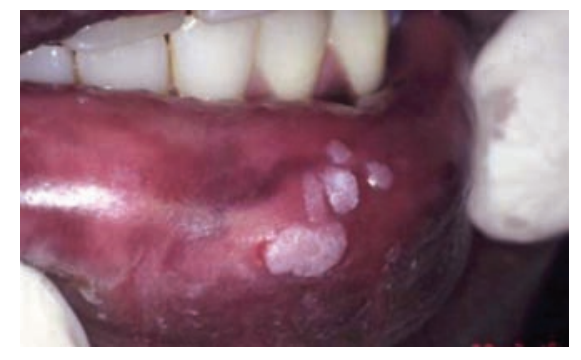

Figure 8. Oral HPV lesion. ${ }^{8}$ Reproduced with permission from IAS-USA. Top HIV Med 2005;13:143-8.

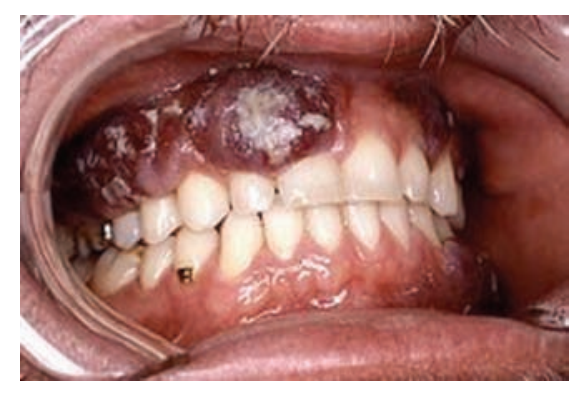

Figure 9. Kaposi's sarcoma. ${ }^{26}$ 
reserved for patients with both oral and extraoral Kaposi's sarcoma. ${ }^{44}$

Non-Hodgkin's lymphoma (NHL) is the second most common malignant condition associated with HIV infection. Lymphomas present as a focal, ulcerated soft tissue mass on the palate or gingival tissues, which may be red and inflamed. The lesions can be painful, and progress rapidly. Suspected lesions are diagnosed with a biopsy, usually under local anesthetic. Management requires systemically administered chemotherapy. Many studies have shown that the $\mathrm{CHOP}$ regimen (cyclophosphamide, doxorubicin, vincristine and prednisone) can be considered the standard approach for patients with aggressive NHL in the context of HIV infection. ${ }^{45,46}$ Surgical debulking may be required for pain relief and improvement of chewing, swallowing, and speech in large exophytic or pedunculated lesions, whereas radiotherapy may be considered for large lesions which cannot be easily accessed. ${ }^{44}$

\section{Neck manifestations of HIV infection}

Cervical lymphadenopathy is the most common manifestation of HIV infection in the neck. In addition to reactive lymphadenitis, cervical lymphadenopathy may result from tuberculosis, lymphoma, or Kaposi's sarcoma in HIV patients. The term HIV lymphadenopathy describes the presence of diffuse lymphadenopathy in two or more sites of the neck for longer than three months. ${ }^{47}$ This can occur in up to $70 \%$ of HIV patients within the first few months after seroconversion, even before any other symptoms of HIV infection appear. The same condition is also seen in children. ${ }^{48}$ The lymph nodes are soft and symmetrical, ranging from 1 to $5 \mathrm{~cm}$ in diameter. They are most frequently observed in the posterior triangle. ${ }^{4}$ The histology is usually suggestive of reactive follicular hyperplasia. Fine needle aspiration is indicated in cases of asymmetry, rapidly enlarged lymph nodes, or any other suspicious features. Biopsy under local or general anesthetic may be necessary in cases of high suspicion for lymphoma. ${ }^{49}$

Salivary gland disease is also not uncommon in HIV-infected patients. It usually involves the parotid glands, tends to be bilateral, sometimes cystic, and can be accompanied by generalized lymphadenopathy. Typically, the patient presents with a history of progressive parotid swelling with minimal tenderness over several months. Salivary gland enlargement occurs in approximately 3 to $30 \%$ of adult patients infected with $\mathrm{HIV}^{39}$ and in up to $30 \%$ of infected children. ${ }^{3}$ This condition may also represent the first clinical manifestation of HIV. Clinical examination should include assessment of the characteristics of the mass (i.e. fixation) and the function of the facial nerve. The three common causes of parotid enlargement in HIV-infected patients are reactive hyperplasia of an intraparotid lymph node, benign lymphoepithelial lesions with ductal metaplasia, and benign lymphoepithelial cysts. $^{50}$ Fine-needle aspiration is an effective method of distinguishing benign from malignant parotid lumps. The most common FNA diagnoses include cystic mass or lymphadenitis and chronic inflammation. ${ }^{50}$

The treatment of salivary gland enlargement in HIV disease still remains controversial. Superficial parotidectomy has been proposed, but has not yet been widely accepted. Aspiration of the cystic lesions can be of some temporary benefit, and injections of tetracycline and doxycycline have been shown to be successful, although with limitations due to the presence of multiple cysts. Alternatively, external irradiation can be considered (24 Gy in 1.5 Gy daily fractions), with overall acceptable cosmetic and long-term functional results. ${ }^{50,51}$

\section{Otological manifestations of HIV infection}

The spectrum of otological manifestations in HIV infection is wide. It involves all three parts of the ear (external, middle, inner), with a cumulative frequency of $20-80 \%$ in both adults and pediatric patients. ${ }^{3,4}$

Indeed, seborrheic dermatitis has been reported in up to $83 \%$ of patients, and usually involves the periauricular area. ${ }^{52,53}$ Otitis externa, on the other hand, is usually caused by Pseudomonas aeruginosa, whilst Candida albicans is often the cause of otomycosis.

Otalgia is a very frequent symptom in HIV patients, which can be attributed to the disproportionately severe inflammatory changes in the mastoid air-cells even in otherwise asymptomatic carriers. ${ }^{52}$ Otitis media with effusion secondary to nasopharyngeal lymphoid hyperplasia or other nasopharyngeal masses is also not uncommon in HIV-positive patients..$^{55,56}$ ever, Kaposi's sarcoma should be excluded. ${ }^{57}$ Acute otitis media may also occur, but is usually seen in patients with end-stage HIV disease. Finally, an increased prevalence of Pneumocystis carinii-infected aural polyps has been reported in HIV patients with chronic otitis media. ${ }^{4}$ Treatment in cases of middle ear infection usually includes broad-spectrum antibiotics, whereas mastoid exploration may be necessary in cases unresponsive to conservative treatment ${ }^{58}$ (Figures 10-12).
Sensorineural hearing loss, either unilateral or bilateral, occurs in $21-49 \%$ of HIV-infected patients. ${ }^{51,59}$ Most patients show down-slopping hearing loss, usually moderate in the high frequencies, whereas speech discrimination is not significantly affected. This type of hearing loss cannot be easily explained, as a histological study of the organ of Corti in HIV patients did not reveal any abnormality, except from some cystic changes in the spiral ligament and stria vascularis. ${ }^{54}$ Possible explanations include the involvement of either retrocohlear pathways, or the cochlear nerve itself. Indeed,

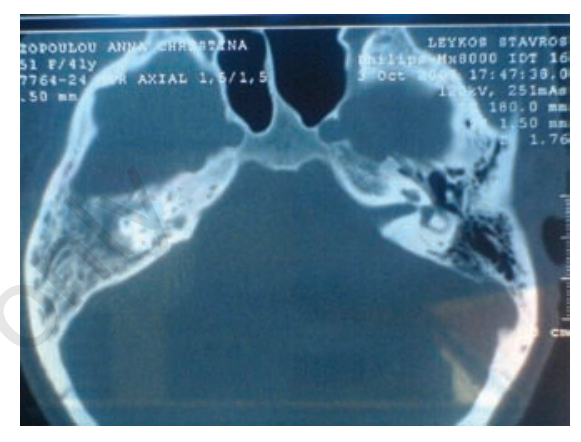

Figure 10. Right mastoiditis (CT scan-axial projection). The patient underwent cortical mastoidectomy.

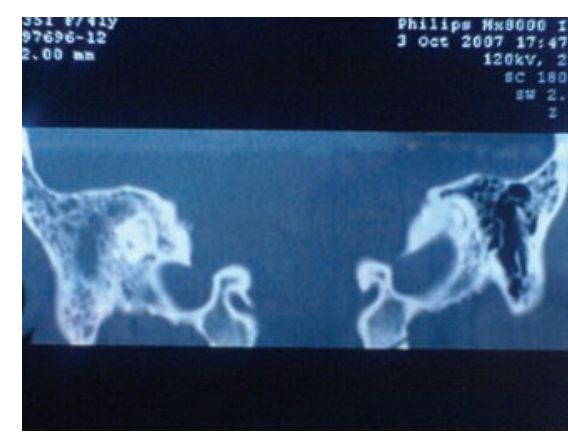

Figure 11. Right mastoiditis (CT scancoronal projection). The patient underwent cortical mastoidectomy.

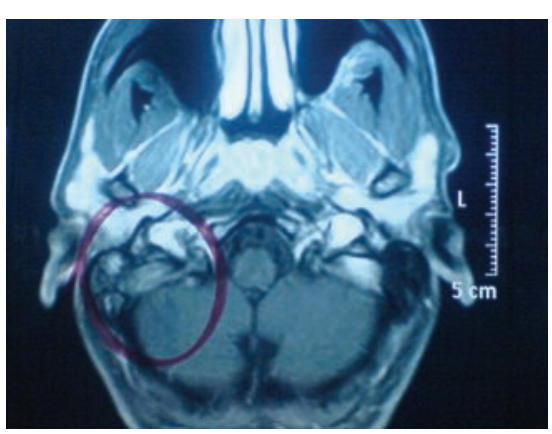

Figure 12. Magnetic resonance imaging scan of the previous patient. Please note the difference in the signal on the right (circle) compared to the left side. 
HIV was shown to induce neuropathological changes and damage to the central nervous system, particularly subcortical demyelination, in a large percentage of infected individuals, even in the absence of gross neurological manifestations. ${ }^{60}$ Other causes of sensorineural hearing loss such as neoplasms, and ototoxic agents should also be excluded. If the hearing loss affects the patient's everyday listening activities and quality of life, the provision of digital hearing aids should be considered.

HIV patients also tend to experience significant disequilibrium, which is also often clinically attributed to central nervous system pathology. However, inner ear abnormalities have also been reported (i.e. sub-epithelial elevation of the neurosensory epithelium of the saccule and utricle, inflammatory endolymphatic precipitations) and may also be important in the pathogenesis of vertigo in these patients..$^{54}$

Finally, unilateral and bilateral facial nerve palsy is a condition that occurs with a 100 -fold greater frequency in the HIV infected population $(4.1 \% \text { vs } 0.04 \%)^{60-62}$ (Table 2). Facial nerve neuropathy can occur at any stage of the HIV infection. It may precede the appearance of HIV antibodies, and seems to occur more frequently in HIV carriers than patients with fullblown AIDS. ${ }^{62-64}$ Peripheral facial nerve neuropathy is usually self-limiting, and may either be idiopathic, or due to herpes virus infection (Ramsey Hunt syndrome). ${ }^{65}$ Treatment includes acyclovir $800 \mathrm{mg}$ five times daily for seven days, and administration of prednisolone $30 \mathrm{mg}$ once daily for five days, with tapering of the starting dose in three-day intervals. Facial nerve palsy can also be seen in endstage patients either as an isolated entity, or as part of multiple cranial nerve involvement. However, it is usually secondary to opportunistic infections or intracranial tumors. ${ }^{66}$

\section{Nasal manifestations of HIV infection}

Nasal manifestations are not uncommon among HIV patients. Indeed, rhinosinusitis seems to occur with a prevalence of $11-70 \%$ in different studies. ${ }^{67-70}$

Although cellular immunity is compromised in AIDS, studies have shown excessive production of IgE, which can be suggestive of allergic rhinitis (in the absence of active parasitic infections). Sample et al. ${ }^{71}$ reported a 2 -fold increase in the incidence of allergic symptoms in HIV-infected men, which may reach $87 \%$ after the infection. Patients typically present with clear rhinorrhea and nasal congestion. Treatment is challenging, due to the risk of iatrogenic Cushing's syndrome from the

Table 2. Prevalence of HIV-associated ear, nose and throat (ENT) manifestation in adults and children.

\begin{tabular}{lcc} 
Common HIV-associated & $\begin{array}{c}\text { Prevalence } \\
\text { in adults }\end{array}$ & $\begin{array}{c}\text { Prevalence } \\
\text { in children }\end{array}$ \\
Oral manifestations & & \\
Oral candidiasis & $30-90 \%$ & $22.5-83.3 \%$ \\
Periodontal and gingival disease & $\leq 4 \%$ & $\leq 20 \%$ \\
Herpes Simplex virus infection & $\leq 9 \%$ & $1.3-24 \%$ \\
Oral hairy leukoplakia & $0.42-38 \%$ & $2 \%$ \\
Neck manifestations & & \\
Cervical lymphadenopathy & $\leq 70 \%$ & $\leq 70 \%$ \\
Parotid gland enlargement & $3-30 \%$ & $\leq 30 \%$ \\
\hline Nasal manifestations & & \\
Allergic rhinitis & $\leq 70 \%$ & n.r. \\
Sinusitis & $30-68 \%$ & $24 \%$ \\
Otological manifestations & & \\
Otitis externa & $5 \%$ & $4 \%$ \\
Otitis media & $13 \%$ & $46 \%$ \\
SNHL & $21-49 \%$ & n.r. \\
Facial nerve palsy & $4.1 \%$ & n.r. \\
\hline
\end{tabular}

n.r., not reported; SNHL, sensorineural hearing loss.

intranasally-administered steroids, in patients receiving ritonavir-containing antiretroviral regimens $^{72}$ (Table 3 ). Budesonide is preferred over fluticasone, due to the significantly longer half-life of the latter, whereas montelukast can be successfully used. ${ }^{71} \mathrm{H}_{1}$-antihistamines can also be considered in patients with HIV..$^{74,75}$

In addition to compromised immunity, impaired mucocilliary clearance has also been reported, and can be held accountable for the high prevalence of rhinosinusitis in HIV patients. ${ }^{67}$ There is no difference in bacteriology compared with the general population, including Streptococcus pneumoniae, Haemophilus influenzae, Moraxella catarrhalis, and Streptococcus viridans in acute episodes, whereas Staphylococcus aureus, Staphylococcus epidermidis, and anaerobes are seen in chronic cases. However, atypical bacteria can also play an important role and need to be considered in the treatment of these patients, especially in cases of decreased CD4 count (i.e. Alternaria alternata, Aspergillus, Pseudallescheria boydii, Cryptococcus, Candida albicans, Acanthamoeba castellani, Microsporidian, and Legionella pneumophila). ${ }^{67}$

Standard outpatient medical therapy with oral antibiotics for three weeks and nasal decongestants are often sufficient. In chronic cases, treatment should last $4-6$ weeks. ${ }^{76}$ Oral antibiotics in cases of acute infection include amoxicillin (standard or high doses), co-amoxiclav (standard or high doses), or cefuroxime. Trimethoprim/sulfamethoxazole or macrolides can be used in $\beta$-lactam-allergic patients, but failure rates are higher. If the response to antibiotic therapy is partial, or when the CD4 count is less than 200 cells per $\mathrm{mm}^{3}$, and in cases of chronic infection, the coverage should be broadened to include pseudomonas, staphy- lococci, and anaerobic species. Appropriate oral treatment in these cases includes the combination of fluoroquinolone and clindamycin or metronidazole. The combination of two antimicrobial agents with activity against Pseudomonas aeruginosa was shown to improve mortality in patients with HIV with Pseudomonas infection, compared with monotherapy. ${ }^{77}$ Patients with persisting symptoms require nasal endoscopy with culture of the obtained swabs, and a CT scan of the sinuses, with the view of performing endoscopic drainage; intravenous antibiotics can also be used. ${ }^{78,79}$ Patients with no improvement after maximal medical treatment can be considered candidates for functional endoscopic sinus surgery, especially when anatomic variations of the nasal and paranasal cavities which predispose to sinus disease are present. ${ }^{80}$ Furthermore, surgical management is required in cases of invasive fungal sinusitis, with debridement of infected bone and tissue, correction of the conditions that predispose to infection, and antifungal medication. The use of liposomal amphotericin B which shows increased cure rates and decreased drug toxicity, compared with conventional amphotericin B therapy, should be preferred. ${ }^{77}$ Washings with solutions containing amphotericine-B and water for injection may also prove useful..$^{81}$

\section{Conclusions}

HIV is a global pandemic that affects millions of adults and children in the developed and developing countries. The prevalence of HIV has risen by $27 \%$ compared to the previous decade, although the annual rate of new cases 
had been steadily declining since the late 1990s.

Up to $80 \%$ of HIV-infected patients eventually develop ENT manifestations. Among ENT manifestations, oral disease seems to be the most common, occurring in approximately 40$50 \%$ of HIV positive patients. Oral candidiasis is by far the most common oral manifestation of HIV infection. Clotrimazole troches, nystatin oral suspension, and nystatin pastilles can be used in the treatment of mild to moderate cases, whereas systemic administration of fluconazole, intraconazole and voriconazole is warranted in moderate to severe cases. Oral HPV infection has also increased in the era of HAART therapeutic regimens, suggesting that a drug or combination of drugs used to treat HIV may be a risk factor for the former. Kaposi's sarcoma is still the most common oral malignancy seen among patients with HIV.
This requires oral hygiene and topical injections of chemotherapeutic agents; surgical removal or radiation therapy can also be considered for treatment.

HIV lymphadenopathy may be the result of reactive lymphadenitis, tuberculosis, lymphoma, or Kaposi's sarcoma, and is the most common manifestation of HIV infection in the neck. Salivary gland disease is also not uncommon, but its treatment still remains controver-

Table 3. Interactions between commonly administered ear, nose and throat medications and antiretroviral drugs. ${ }^{73}$

\begin{tabular}{ll}
\hline BNI medication & Interaction with antiretroviral drug/potential clinical effects \\
Itraconazole & Inhibition of CYP450 3A4 \\
& Increased darunavir and itraconazole effects when itraconazole is combined \\
& with darunavir (darunavir also inhibits CYP450 3A4) \\
& Decreased itraconazole effects when combined with didanosine, \\
& (decreased gastric acidity from the antacid buffer contained within didanosine \\
& tablets/suspension resulting in decreased itraconazole absorption) \\
& Decreased itraconazole effects when combined with efavirenz (efavirenz induces CYP450 3A4) \\
& Increased indinavir effects when combined with indinavir (due to CYP450 3A4 inhibition) \\
& Increased lopinavir/ritonavir and itraconazole effects when combined with lopinavir/ritonavir \\
& (lopinavir/ritonavir also inhibits CYP450 3A4) \\
& Increased ritonavir effects when combined with ritonavir (due to CYP450 3A4 inhibition) \\
& Increased saquinavir and itraconazole effects when combined with saquinavir \\
& (saquinavir also inhibits CYP450 3A4)
\end{tabular}

\begin{tabular}{|c|c|c|}
\hline Voriconazole & $\begin{array}{l}\text { Inhibition of CYP450 } 3 \mathrm{~A} 4 \\
\text { Decreased yoriconazole effects when combined with atazanavir/ darunavir } \\
\text { (due to possible induction of CYP450) } \\
\text { Possibly increased etravirine effects when combined with etravirine: } \\
\text { (due to CYP450 3A4 inhibition) } \\
\text { Decreased voriconazole levels when combined with lopinavir/ritonavir } \\
\text { (due to possible induction of CYP450 by ritonavir) } \\
\text { Decreased voriconazole effects when combined with ritonavir } \\
\text { (due to induction of CYP450 3A4) } \\
\text { Decreased voriconazole effects and increased efavirenz effects when combined } \\
\text { with efavirenz (efavirenz induces CYP450 3A4) }\end{array}$ & $\begin{array}{l}\text { Do not co-administer with atazanavir/ darunavir } \\
\text { No dose adjustment is necessary when combined } \\
\text { with etravirine } \\
\text { Do not co-administer with lopinavir/ritonavir } \\
\text { Avoid co-administration with ritonavir } \\
\text { Do not co-administer with efavirenz at standard doses; } \\
\text { increase voriconazole to } 400 \mathrm{mg} \text { bd, and decrease } \\
\text { efavirenz to } 300 \mathrm{mg} \text { QHS }\end{array}$ \\
\hline Fluconazole & $\begin{array}{l}\text { Inhibition of CYP450 3A4 } \\
\text { Increased etravirine, nevirapine, saquinavir, tipranavir, zidovudine effects }\end{array}$ & No dose adjustment necessary \\
\hline Ketoconazole & $\begin{array}{l}\text { Inhibition of CYP450 } 3 \mathrm{~A} 4 \\
\text { Increased darunavir and ketoconazole effects when ketoconazole is combined } \\
\text { with darunavir (darunavir also inhibits CYP450 3A4) } \\
\text { Increased delavirdine effects when combined with delavirdine } \\
\text { (due to CYP450 3A4 inhibition) } \\
\text { When combined with didanosine, possibly decreased didanosine effects } \\
\text { (decreased gastric acidity from the antacid buffer contained within didanosine } \\
\text { tablets/suspension resulting in decreased ketoconazole absorption) } \\
\text { Decreased ketoconazole effects when combined with efavirenz } \\
\text { (efavirenz induces CYP450 3A4) } \\
\text { Increased indinavir effects when combined with indinavir } \\
\text { (due to CYP450 3A4 inhibition) } \\
\text { When combined with lopinavir/ritonavir, increased ketoconazole effects, } \\
\text { and decreased lopinavir/ritonavir effects } \\
\text { Increased maraviroc effects when combined with maraviroc } \\
\text { (due to CYP450 3A4 inhibition) } \\
\text { Increased nelfinavir effects when combined with nelfinavir } \\
\text { (due to CYP450 3A4 inhibition) } \\
\text { Decreased ketoconazole effects when combined with nevirapine } \\
\text { (nevirapine induces CYP450 3A4) } \\
\text { Decreased ketoconazole effects when combined with rilpivirine } \\
\text { Increased ritonavir/ saquinavir effects when combined with ritonavir/ } \\
\text { saquinavir (due to CYP450 3A4 inhibition) }\end{array}$ & $\begin{array}{l}\text { Dose adjustment when combined with darunavir } \\
\text { is not established } \\
\text { If co-administration is required, the dose } \\
\text { of ketoconazole should not exceed } 200 \mathrm{mg} \text { daily } \\
\text { No dose adjustment necessary when combined } \\
\text { with delavirdine } \\
\text { Consider didanosine EC } \\
\text { Administer ketoconazole at least } 2 \mathrm{~h} \\
\text { prior to didanosine tablets/suspension } \\
\text { Do not co-administer with efavirenz } \\
\text { Consider decreasing indinavir to } 600 \text { mg tds } \\
\text { Manufacturer recommends against using high } \\
\text { doses of ketoconazole (including drops) with } \\
\text { lopinavir/ritonavir (200 mg daily) } \\
\text { Reduce maraviroc dose to } 150 \text { mg bd when used } \\
\text { with ketoconazol } \\
\text { No dose adjustment necessary when } \\
\text { combined with nelfinavir } \\
\text { Do not co-administer with nevirapine } \\
\text { No dose adjustment necessary when combined } \\
\text { with rilpivirine, but monitoring for potential failure } \\
\text { of antifungal therapy is required } \\
\text { Dose adjustment when combined with ritonavir/ } \\
\text { saquinavir is not established }\end{array}$ \\
\hline
\end{tabular}

If co-administration with darunavir is required, the dose of itraconazole should not exceed $200 \mathrm{mg}$ daily Administer itraconazole capsules at least $2 \mathrm{~h}$ after didanosine tablets/suspension

Do not co-administer with efavirenz Decrease indinavir to $600 \mathrm{mg}$ tds

) Do not exceed itraconazole $200 \mathrm{mg}$ bd

Manufacturer recommends against using high doses of itraconazole (including drops) with lopinavir/ritonavir (200 mg daily)

Dose adjustment when combined with

ritanovir is not established

Consider reducing itraconazole to $100 \mathrm{mg}$ bd when combined with saquinavir

\section{Do not co-administer with atazanavir/ darunavir}

o dose adjustment is necessary when combined etravirine Avoid co-administration with ritonavir increase voriconazole to $400 \mathrm{mg}$ bd, and decrease efavirenz to $300 \mathrm{mg} \mathrm{QHS}$

Decreased voriconazole effects when combined with ritonavir

Decreased voriconazole effects and increased efavirenz effects when combined

Inhibition of CYP450 3A4

Inhibition of CYP450 3A4

Increased darunavir and ketoconazole effects when ketoconazole is combined

darunavir (darunavir also inhibits CYP450 3A4)

due to CYP450 3A4 inhibition)

When combined with didanosine, possibly decreased didanosine effects

tablets/suspension resulting in decreased ketoconazole absorption)

Decreased ketoconazole effects when combined with efavirenz

(efavirenz induces CYP450 3A4)

ncreased indinavir effects when combined with indinavir

When combined with lopinavir/ritonavir, increased ketoconazole effects, and decreased lopinavir/ritonavir effects

Increased maraviroc effects when combined with maraviroc

(due to CYP450 3 A4 inhibition)

(due to CYP450 3A4 inhibition)

Decreased ketoconazole effects when combined with nevirapine

Increased ritonavir/ saquinavir effects when combined with ritonavir/ saquinavir (due to CYP450 3A4 inhibition)
Dose adjustment when combined with darunavir is not established

Consider didanosine EC

Administer ketoconazole at least $2 \mathrm{~h}$

Consider decreasing indinavir to $600 \mathrm{mg}$ tds lopinavir/ritonavir (200 mg daily)

Reduce maraviroc dose to $150 \mathrm{mg}$ bd when used with ketoconazol

combined with nelfinavir

Do not co-administer with nevirapine with rilpivirine, but monitoring for potential failure ant required saquinavir is not established

CYP450, cytochrome P450 enzyme complex-family 3-subfamily A-polypeptide 4; bd, twice daily; tds, every 8 h; QHS, at bedtime. 
sial in the presence of HIV disease. Superficial parotidectomy has been proposed, and external irradiation seems to provide overall acceptable cosmetic and long-term functional results.

Otalgia is a very frequent symptom in HIV patients. Acute otitis media is usually seen in patients with end-stage HIV disease and usually requires broad-spectrum antibiotics. Mastoid exploration is reserved for unresponsive cases. HIV patients also tend to experience a 100 -fold greater frequency of unilateral and bilateral facial nerve palsy, which usually requires treatment with acyclovir and prednisolone (in a tapered dosologic regimen).

Finally, nasal manifestations are also not uncommon among HIV patients. Although there is no difference in the bacteriology of rhinosinusitis compared with the general population, atypical bacteria can also play an important role and need to be considered in patient treatment, especially in cases of decreased CD4 count. Oral antibiotics in cases of acute infection include amoxicillin, coamoxiclav, or cefuroxime, whereas trimethoprim/sulfamethoxazole or macrolides can be used in cases of allergy. In cases of chronic infection or low CD4 count, the combination of fluoroquinolone and clindamycin or metronidazole should be considered. Patients with no improvement after maximal medical treatment, and cases of invasive fungal sinusitis are considered candidates for functional endoscopic sinus surgery.

Although ENT symptoms are not diagnostic of the disease, they might be suggestive of HIV infection, or related to its progression and the respective treatment failure. In the era of HAART ENT manifestations of HIV have been reduced, but still affect a significant proportion of HIV infected people. It is important that ENT doctors are aware of the ENT conditions associated with HIV disease, and the respective diagnosis and treatment. A multi-disciplinary approach may be required to provide the appropriate level of care to HIV patients.

\section{References}

1. UNAIDS. Report on the global AIDS epidemic. 2010.

2. Baccaglini L, Atkinson JC, Patton LL, et al. Management of oral lesions in HIV-positive pacients. Oral Surg Oral Med Oral Pathol Oral Radiol Endod 2007;103:S50.e1-S50e23.

3. Williams MA. Head and neck findings in pediatric acquired immune deficiency syndrome. Laryngoscope. 1987;97:713-6

4. Prasad HK, Bhojwani KM, Shenoy V, Prasad SC. HIV manifestations in otolaryngology. Am J Otolaryngol-Head and Neck Med and
Surg 2006;27:179-85.

5. Johnson NW, Glick M, Mbuguye TNL. Oral health and general health. Adv Dent Res 2006;19:118-21.

6. Tappuni AR, Flemnming GJ. The effect of antiretroviral therapy on the prevalence of oral manifestations in HIV-infected patients: a UK study. Oral Surg Oral Med Oral Pathol Oral Radiol Endod 2001;92:6238.

7. Hodgson TA, Greenspan D, Greenspan JS. Oral lesions of HIV disease and HAART in industrialized countries. Adv Dent Res 2006;19:57-62.

8. Reznik DA. Oral manifestations of HIV disease. Top HIV Med 2005;13:143-8.

9. Miziara ID, Weber R. Oral candidosis and oral hairy leukoplakia a predictors of HAART failure in Brazilian HIV-infected patients. Oral Dis 2006;12:402-7.

10. Ramirez-Amador V, Ponce-de-Leon S, Anaya-Saavedra G, et al. Oral Lesions as Clinical Markers of Highly Active Antiretroviral Therapy Failure: A Nested Case-Control Study in Mexico City. Clin Infect Dis. 2007;45:925-32.

11. Silverman Jr S, Migliorati CA, Lozada-Nur F, et al. Oral findings in people with or at high risk for AIDS: a study of 375 homosexual males. J Am Dent Assoc 1986;112:18792.

12. Phelan JA, Saltzman BR, Friedland GH, et al. Oral findings in patients with acquired immunodeficiency syndrome. Oral Surg Oral Med Oral Pathol 1987;64:50-6.

13. Naidoo S, Chikte U. Oro-facial manifestations in paediatric HIV: a comparative study of institutionalized and hospital outpatients. Oral Dis 2004;10:13-8.

14. Cherry-Peppers G, Daniels C0, Meeks V, Sanders CF, Reznik D. Oral manifestations in the era of HAART. J Natl Med Assoc 2003; 95:21S-32S.

15. Ranganathan K, Hemalatha R. Oral lesions in HIV infection in developing countries: an overview. Adv Dent Res 2006;19:63-8.

16. Johnson NW. The mouth in HIV/AIDS: markers of disease status and management challenges for the dental profession. Australian Dent J 2010;55:85-102.

17. Pienaar ED, Young T, Holmes $H$. Interventions for the prevention and management of oropharyngeal candidiasis associated with HIV infection in adults and children. (Cochrane Review). In: The Cochrane Library, Issue 3, Oxford, 2007: Update Software.

18. Leggott PJ, Robertson PB, Greenspan D, et al. Oral manifestations of primary and acquired immunodeficiency diseases in children. Pediatr Dent. 1987;9:98-104.

19. Ranganathan K, Reddy BV, Kumarasamy N, et al. Oral lesions and conditions associated with human immunodeficiency virus infec- tion in 300 south Indian patients. Oral Dis 2000;6:152-7.

20. Flaitz C, Wullbrandt B, Sexton J, et al. Prevalence of orodental findings in HIVinfected Romanian children. Pediatr Dent 2001;23:44-50.

21. Lamster IB, Grbic JT, Mitchell-Lewis DA, et al. New concepts regarding the pathogenesis of periodontal disease in HIV infection. Ann Periodontol 1998;3:62-75.

22. Yeung SC. HIV infection and periodontal disease. Ann R Australas Coll Dent Surg 2000;15:331-4.

23. Glick M, Muzyka BC, Salon LM, Luric D. Necrotizing ulcerative periodontitis: a marker for severe immune deterioration. J Periodontol 1994;65:393-7.

24. Winkler JR, Robertson PB. Periodontal disease associated with HIV infection. Oral Surg Oral Med Oral Pathol 1992;73:145-50.

25. American Dental Association. Dental management of the HIV-infected patient. J Am Dent Assoc 1995;126:1-39.

26. Kline MW. Oral manifestiations of pediatric human inmunodeficiecy virus infection: a review of de la literature. Pediatrics 1996;97:380-8.

27. Wikipedia ${ }^{\mathrm{TM}}$ The free encyclopedia.

28. Santos LC, Castro GF, De Souza IP, Oliveira RH. Oral manifestations related to immunosuppresion degree in HIV-positive children. Braz Dent J 2001;12:135-8.

29. Flaitz CM, Hicks MJ, Carter AB, et al. Saliva collection technique for cytologic, microbiologic and viral evaluation in pediatric HIV infection. ASDC J Dent Child 1998;65:31824.

30. Leggott PJ. Oral manifestations of HIV infection in children. Oral Surg Oral Med Oral Pathol 1992;73:187-92.

31. Sroussi HY, EpsteinJB. Changes in the pattern of oral lesionsassociated with HIV infection: Implications for dentists. JCDA 2008;73:949-52.

32. Arendorf T, Holmes H. Oral manifestations associated with human immunodeficiency virus (HIV) infection in developing countries - are there differences from developed countries? Oral Dis 2000;6:133-5.

33. Greenspan JS, Greenspan D. The epidemiology of the oral lesions of HIV infection in the developed world. Oral Dis 2002;8:34-9.

34. Patton L, Hill C. Sensitivity, specificity, and positive predictive value of oral oppurtunistic infections in adults with HIV/AIDS as markers of immune suppression and viral burden. Oral Surg Oral Med Oral Pathol Oral Radiol Endod 2004;90:182-8.

35. Nishio CE, Petri V, Narahashi E. Oral hairy leukoplakia: topical use of trichloracetic and glycolic acids - results. In: 10th International Conference on AIDS, Yokohama, Japan, 1994.

36. Gowdey G, Lee RK, Carpenter WM. 
Treatment of HIV-related hairy leukoplakia with podophyllum resin $25 \%$ solution. Oral Surg Oral Med Oral Pathol Oral Radiol Endod 1996;79:64-7.

37. Bartlett JG. The Johns Hopkins Hospital Guide to Medical Care of Patients with HIV Infection. 4th ed. Williams \& Wilkins, Baltimore, 1994.

38. Diz Dios P, OcampoA, Miralles C. Changing prevalence of human immunodeficiency virus-associated oral lesions. Oral Surg Oral Med Oral Pathol Oral Radiol Endod 2000;4034.

39. Patton LL, McKaig R, Straauss R, et al. Changing prevalence of oral manifestations of human immunodeficiency virus in the era of protease inhibitor therapy. Oral Surg Oral Med Oral Pathol Oral Radiol Endod 2000; 90:299-304.

40. Syrjänen S. Human papillomavirus infection and its association with HIV. Adv Dent Res 2011;23:84-9

41. Leao JC, Ribeiro CMB, Carvalho AAT, et al. Oral complications of HIV disease. Clinics 2009;64:459-70.

42. Schweitzer VG, Visscher D. Photodynamic therapy for treatment of AIDS-related oral Kaposi's sarcoma. Otolaryngol Head Neck Surg J 1990;102:639-49.

43. Singh B, Lucente FE. Kaposi's sarcoma of the head and neck inpatients with acquired immunodeficiency syndrome. Otolaryngol Head Neck Surg J 1994;111:618-24.

44. Weinert M, Grimes RM, Lynch DP. Oral Manifestations of HIV Infection. Ann Intern Med 1996;125:485-96.

45. Fisher RI, Gaynor ER, Dahlberg S et al. Comparison of a standard regimen (CHOP) with three intensive chemotherapy regimens for advanced non-Hodgkin's lymphoma. N Engl J Med 1993;328:1002-6.

46. Gisselbrecht C, Spina M, Gabarre J et al. Therapy of HIV-related non-Hodgkin's lymphoma: an European multicentric randomized study in patients stratified according to their prognostic factors: preliminary results. J Acquir Immune Defic Syndr 1997;14:abstract 149.

47. Lee KC, Cheung CW. Evaluation of the neck mass in the human immunodeficiency virus- infected patients. Otolaryngol Clin North Am 1992;25:1287- 305.

48. Singh A, Georgalas C, Papel N, Papesh M. ENT presentations in children with HIV infection. Clin Otolaryngol 2003;28:240-3.

49. Abrams DI. AIDS-related lymphadenopathy: the role of biopsy. J Clin Oncol 1986;4:1267.

50. Casiano RR, Cooper JD, Gould E, et al. Value of needle biopsy directing management of parotid lesions in HIV- positive patients. Head Neck J 1991;13:411-4.

51. Beirler JJ, Vikram B, Silver CE, et al. (1995) Low-dose radiotherapy for multicystic benign lymphoepithelial lesions of the parotid gland in HIV- positive patients: Long- term results. Head Neck J 1995;17:315.

52. Lalwani AK, Sooy CD. Otologic and neurotologic manifestations of acquired immunodeficiency syndrome. Otolaryngol Clin North Am 1992;25:1183-97.

53. Kaplan MH, Sadick N, McNutt NS, et al. Dermatologic findings and manifestations of acquired immunodeficiency syndrome (AIDS). J Am Acad Dermatol 1987;16:485506.

54. Chandrasekhar SS, Siverls V, Chandra Sekhar H. Histopathologic and ultrastructural changes in the temporal bones of HIVinfected human adults. Am J Otol 1992;13:207-14.

55. Frick OL. Role of viral infections in asthma and allergy. Clinical Review in Allergy 1983;1:5-17.

56. Miziara ID, Weber R, Cunha Filho BA, Pinheiro Neto CD. Otitis media in Brazilian human immunodeficiency virus infected children undergoing antiretroviral therapy. J Laryngol Otol 2007;121:1048-54.

57. Lanser MJ, Klein ZH, Marvin A. Kaposi's sarcoma in patients with AIDS. Arch Otolaryngol 1985;111:486-9.

58. Kampessis G, Vlastarakos PV, Papanikolaou P, et al. Bilateral acute mastoiditis in an HIV-Positive patient. Skull Base 2009;19:10.

59. Newton JP. The causes of hearing loss in HIV infection. Community Ear and Hearing Health 2006;3:1-16.

60. Anders K, Guerra WF, Tomiyasu U, et al. The neuropathology of AIDS. UCLA experience and review. Am J Pathol 1986;124:537-58.

61. Kim MS, Yoon HJ, Kim HJ, et al. Bilateral peripheral facial palsy in a patient with Human Immunodeficiency Virus (HIV) infection. Med J 2006;47:745-7.

62. Belec L, Georges AJ, Vuillecard E, et al. Peripheral facial paralysis indicating HIV infection. Lancet 1988;2:1421-2.

63. Sasaki MG, Leite PGB, Leite AGB, et al. Bilateral peripheral facial palsysecondary to lymphoma in a patient with HIV/AIDS: A case report and literature review. BJID $2002 ; 6: 50-4$

64. Abboud 0, Saliba I. Isolated bilateral facial paralysis revealing AIDS: a unique presentation. Laryngoscope 2008;118:580-4.

65. Goldani LZ, da Silva LF, Dora JM Ramsay Hunt syndrome in patients infected with human immunodeficiency virus. Clin Exp Dermatol 2009;34:e552-4.

66. Chand V, Sweeney C, Agger WA. Mental neuropathy in patients with AIDS associated malignant lymphoma. Clin Inf Dis 1997;24:521-2.

67. Tami TA, Wawrose S. Diseases of the nose and paranasal sinus in the acquired immunodeficiency virus-infected popula- tion. Otolaryngol Clin North Am 1992;25:1199- 210.

68. Campanini A, Marani M, Mastroianni A, et al. Human immunodeficiency virus infection: personal experience in changes in head and neck manifestations due to recent antiretroviral therapies. Acta Otorhinolaryngol Ital 2005;25:30-5

69. Sanjar FA, Queiroz BE, Miziara ID. Otolaryngologic manifestations in HIV disease--clinical aspects and treatment. Braz J Otorhinolaryngol 2011;77:391-400.

70. Miziara ID, Araujo Filho BC, La Cortina RC, et al. Chronic rhinosinusitis in HIV-infected patients: radiological and clinical evaluation. Rev Bras Otorrinolaringol 2005; $7: 604-8$.

71. Sample S, Chernoff DN, Lenahan GA, et al. Elevated serum concentrations of IgE antibodies to environmental antigens in HIVseropositive male homosexuals. J Allergy Clin Immunol 1990;86:876-80.

72. Kedem E, Shahar E, Hassoun G, Pollack S. Iatrogenic Cushing's syndrome due to coadministration of ritonavir and inhaled budesonide in an asthmatic human immunodeficiency virus infected patient. J Asthma 2010;47:830-1.

73. HIV Insite: project of the University of California San Francisco center for HIV information. Available from: http:/hivinsite.ucsf.edu

74. Van Heeswijk RP, Bourbeau M, Campbell P et al. (2006) Time-dependent interaction between lopinavir/ritonavir and fexofenadine. J Clin Pharmacol 2006;46:758-67.

75. Been-Tiktak AM, Boucher CA, Brun-Vezinet F, et al. Efficacy and safety of combination therapy with delavirdine and zidovudine: a European/Australian phase II trial. Int J Antimicrob Agents 1999;11:13-21.

76. Gurney TA, Lee KC, Murr AH. Contemporary issues in rhinosinusitis and HIV infection. Curr Opin Otolaryngol. Head Neck Surg 2003;11:45-8.

77. Sinus and Allergy Health Partnership. Antimicrobial treatment guidelines for acute bacterial rhinosinusitis. Otolaryngol Head Neck Surg 2004;130:1-45.

78. HIV InSite Knowledge Base. Available from http://hivinsite.ucsf.edu/InSite?page $=\mathrm{kb}$ 04-01-13\#S7.5X

79. Friedman $\mathrm{M}$, Landsberg $\mathrm{R}$, Tanyeri $\mathrm{H}$, et al. Endoscopic sinus surgery in patients with HIV. Laryngoscope 2000;110:1613-6.

80. Shah AR, Hairston JA, Tami TA. Sinusitis in HIV: Microbiology and Therapy. Current Allergy and Asthma Report 2005;5:495-9.

81. Vlastarakos PV, Manolopoulos L, Ferekidis E, et al. Treating common problems of the nose and throat in pregnancy: what is safe? Eur Arch Otorhinolaryngol 2008;265: 499508 . 